\title{
Characteristics of temperature changes in photothermal therapy induced by combined application of indocyanine green and laser
}

\author{
SHAN LONG ${ }^{1 *}$, YUANYUAN XU ${ }^{1 *}$, FEIFAN ZHOU ${ }^{2}$, BO WANG $^{1}$, \\ YUNNING YANG $^{1}$, YAN FU ${ }^{1}$, NAN DU ${ }^{1}$ and XIAOSONG $\mathrm{LI}^{1}$ \\ ${ }^{1}$ Department of Oncology, The Fourth Medical Center of Chinese People's Liberation Army General \\ Hospital, Beijing 100048, P.R. China; ${ }^{2}$ Biophotonics Research Laboratory Center for Interdisciplinary \\ Biomedical Education and Research University of Central Oklahoma, Edmond, OK 73034, USA
}

Received February 11, 2018; Accepted December 19, 2018

DOI: $10.3892 / 01.2019 .10058$

\begin{abstract}
Photothermal therapy, a type of laser application, has the ability to eradicate tumor cells by a local thermal effect and elicit a tumor specific immune response. Indocyanine green (ICG), a photosensitizer, can effectively elevate the local temperature by absorbing energy from the laser. The present study aimed to investigate the characteristics of temperature changes during photothermal therapy with an infrared thermometer in an ICG solution and in tumor-bearing mice treated with a combination of laser and ICG. Additionally, the present study observed the morphological changes of tumor tissue by hematoxylin-eosin staining following photothermal therapy. In the solution experiment, when the laser power density was $1 \mathrm{~W} / \mathrm{cm}^{2}$ and the concentration of ICG was 0 or $0.0187 \mathrm{mg} / \mathrm{ml}$, the temperature of the water was elevated by 3 and $28^{\circ} \mathrm{C}$, respectively. In the tumor-bearing mice experiment, when the laser power density was $1 \mathrm{~W} / \mathrm{cm}^{2}$ and the concentration of ICG was 0 and $0.1 \mathrm{mg} / \mathrm{ml}$, the temperature of the tumor-bearing mice was elevated by 6.9 and $28.5^{\circ} \mathrm{C}$, respectively. With an increase in laser power density, including $0.6,0.8$ and $1.0 \mathrm{~W} / \mathrm{cm}^{2}$, the temperature was $23.3,26.7$ and $28.5^{\circ} \mathrm{C}$, respectively. Pathological tissue sections demonstrated that a large number of tumor cells experienced necrosis, and the envelope of the tumor was destroyed. Numerous inflammatory cells, in particular lymphocytes, infiltrated into the tumor tissue following tumor tissue treatment with a combination of laser and ICG. These results indicated that a combination treatment with laser and ICG may significantly increase the temperature of the water solutions and in the tumor-bearing mice. The
\end{abstract}

Correspondence to: Dr Xiaosong Li, Department of Oncology, The Fourth Medical Center of Chinese People's Liberation Army General Hospital, 51 Fucheng Road, Beijing 100048, P.R. China E-mail: lixiaosong@hotmail.com

*Contributed equally

Key words: photothermal therapy, temperature change, laser, indocyanine green concentration of ICG and laser power density contributed to the temperature elevation, in particular to the concentration of ICG.

\section{Introduction}

Cancer has been reported as the leading health risk worldwide in 2018 (1). In 2017, there were 1,688,780 cancer cases in the USA. Additionally, 600,920 patients died from cancer in 2017 (1). In the past three decades, an improvement in the 5-year survival rate has been reported. However, cancer remains the second leading cause of cancer-associated mortality in USA (1). The ideal cancer treatment modality should not only kill local tumor cells with limited or no damage to surrounding normal tissue, but also induce metastatic tumors to regress, preventing tumor recurrences (2). Laser immunotherapy has the potential to be an ideal cancer treatment modality (3).

Laser immunotherapy was established and applied the first time in 1997 (4). It is a convenient, minimally invasive cancer therapy strategy that damages targeted tumors by hyperthermia and subsequently elicits a personalized tumor-specific immune response (4). Laser immunotherapy consists of a combination of photothermal therapy and immunotherapy. Photothermal therapy, which has also been referred to as a photothermal interaction, is an important part of laser immunotherapy. The photothermal effect primarily focuses on noninvasive near-infrared (NIR) light, which delivers energy to the targeted tumor tissues. A photosensitizer absorbs the energy in the tumor tissue, causing an elevation in temperature in the targeted tissue (4). The elevated temperature kills local tumor cells, subsequently releasing tumor antigens to activate the immune system (5).

Indocyanine green (ICG) is a water-soluble tricarbocyanine dye that serves as a photosensitizer (6). The ICG solution is injected into the center of neoplastic tissues prior to irradiation, which subsequently increases the temperature of the tissue and results in selective destruction, leaving the surrounding tissue relatively undamaged. The heat energy transferred from the laser energy produces a strong photothermal interaction (7).

Laser immunotherapy has attained a promising treatment effect in animal experiments and clinical trials $(6,8)$. In animal 
experiments, the combination of laser immunotherapy and surgery significantly extended the survival time of EMT6 tumor bearing BALB/c mice, which rejected successfully the following two consecutive challenges with EMT6 cells (4). In a clinical trial, patients were reported to respond well to laser immunotherapy during their treatment of metastatic breast cancer (7). It was reported in the aforementioned study that laser immunotherapy exhibited a promising effect on the objective response rate, in addition to the clinical beneficial response rate of these patients (7). These promising effects were primarily due to the photothermal therapy that selectively targeted and directly eradicated the tumor cells (9). Additionally, it has been reported that tumor cells damaged by high temperatures can activate an immune response by releasing tumor cell debris and byproducts (10).

However, the thermal effects and immune effects induced by thermotherapy require further investigation, as different temperatures produce different thermal and immune effects. If the temperature is insufficient, the tumor cells are not destroyed, whereas if the temperature is too high, the surface tissue may be damaged and impede further infiltration of laser energy (11). The temperature increase in the tumor cells is primarily determined by the laser power density, ICG concentration and laser irradiation time (12). A number of studies demonstrated that the thermal effect is induced by the combination of laser and ICG (13-15); however, the characteristics of temperature changes during photothermal therapy have not been extensively investigated.

The present study aimed to investigate the absorption spectrum of ICG and subsequently examine the characteristics of temperature changes during the exposure of ICG to a laser in water solution and tumor-bearing mice. The present study also aimed to observe the morphological changes of tumor tissues following thermal therapy.

\section{Materials and methods}

ICG. ICG, obtained from Akorn Inc. (Buffalo Grove, IL), is a tricarbocyanine dye and was used as a photosensitizer in this study. The ultraviolet-visible near infrared absorbance spectra of ICG was recorded by a Perkin Elmer Lambda 750 ultraviolet-visible-NIR spectrophotometer (PerkinElmer, Inc., Waltham, MA, USA). A total of 5 different dilutions of ICG, including $10,5,2.5,1.25$, and $0.3725 \mu \mathrm{g} / \mathrm{ml}$, were used for detecting the absorption spectrum.

Tumor cell line. The breast tumor cell line 4T1 (mouse mammary gland, ATCCCRL-2534 4T1) was cultured in Roswell Park Memorial Institute 1640 (RPMI 1640) medium (Invitrogen, Carlsbad, CA) with $10 \%$ fetal bovine serum (AppliChem GmbH, Darmstadt, Germany), $100 \mathrm{U} / \mathrm{ml}$ penicillin and $100 \mathrm{U} / \mathrm{ml}$ streptomycin (Sigma-Aldrich; Merck $\mathrm{KGaA}$, Darmstadt, Germany) at $37^{\circ} \mathrm{C}$ with $5 \% \mathrm{CO}_{2}$ for $48 \mathrm{~h}$. The cells were harvested and prepared in this medium $\left(1 \times 10^{6}\right.$ cells $\left./ 100 \mu \mathrm{l}\right)$ for injection.

Animal model. Female BALB/c mice (6-8 weeks; 15-25 g) were used in the present experiment. A total of 12 mice were kept in specific pathogen-free animal facilities with controlled temperature and humidity under conventional conditions at a temperature of $22 \pm 2^{\circ} \mathrm{C}$, a relative humidity of $55 \pm 10 \%$ and a $12 \mathrm{~h}$ dark/light illumination cycle. Water and food were available ad libitum. They were fed standard diet chow pellets and water ad libitum. The mice were purchased from Harlan Sprague Dawley Co. (Indianapolis, IN, USA). The mice were housed and performed in Biophotonics Research Laboratory Center for Interdisciplinary Biomedical Education and Research University of Central Oklahoma (Edmond, OK, USA). The mice were anesthetized with a gas mixture of isoflurane $(2 \%)$ and oxygen (2 1/min) prior to laser irradiation. Following the completion of laser irradiation, the mice were allowed to recover for $30 \mathrm{~min}$. All animal experiments were approved by the Institutional Animal Care and Use Committee of Biophotonics Research Laboratory Center for Interdisciplinary Biomedical Education and Research University of Central Oklahoma (OK, USA) and were in accordance with National Institutes of Health guidelines (16). The hair of the BALB/c mice was removed and the mice were subcutaneously injected with $1 \times 10^{6} 4 \mathrm{~T} 1$ cells suspended in $100 \mu \mathrm{l}$ of PBS. Tumors grew predictably in all mice and reached a size of $5-10 \mathrm{~mm}$ in diameter between 8 to 10 days following injection. Tumor growth was assessed 2 times a week from inoculation of tumor cells to mortality. The orthogonal tumor dimensions ( $\mathrm{a}$ and $\mathrm{b}$ ) were measured with a Vernier caliper. The tumor volume was calculated according to the formula $V=a b^{2} / 2$, where ' $a$ ' is the maximum diameter of the tumor and ' $b$ ' is the smallest diameter of the tumor (17). The tumor bearing mice were ready for the treatment when the tumors reached a volume of $100-250 \mathrm{~mm}^{3}$. Mice were monitored carefully throughout the study and were preemptively euthanized by cervical dislocation when they became moribund.

Treatment parameters and procedures of laser thermotherapy in solution. A Laser with a wavelength of $805 \mathrm{~nm}$ (ImmunoPhotonics Inc., Columbia, MO, USA) was used in this study. The laser energy was delivered by an optical fiber. There is a control device that is incorporated into the handle at the end of the optical fiber that can be adjusted to deliver various power densities.

In the solution experiment, solutions with different concentrations of ICG, including 10, 5, 2.5, 1.25 and $0.3725 \mu \mathrm{g} / \mathrm{ml}$, were irradiated by NIR laser diode at a wavelength $805 \mathrm{~nm}$ with $1 \mathrm{~W} / \mathrm{cm}^{2}$ output. The detailed parameters of the ICG solution are included in Table I. Aforementioned solution $(\sim 1 \mathrm{ml})$ were prepared in conical tubes and irradiated with the $805 \mathrm{~nm}$ laser for $120 \mathrm{sec}$. The surface temperature of the solution was monitored by an infrared thermometer 2017 (FLIR ${ }^{\circledR}$ Systems, Inc, Wilsonville, OR, USA). It was used to detect the temperature at the irradiation time points of $0,10,20,30,40,50,60$, $70,80,90,100,110$ and $120 \mathrm{sec}$.

Treatment parameters and procedures of laser thermotherapy in tumor-bearing mice. In the animal experiment, various parameters of power density and ICG concentrations were used to treat the 4T1 tumor-bearing BALB/c mice. The detailed parameters of the different components for the treatment of tumor bearing mice are presented in Table II. Prior to the laser treatment, the 4T1 tumor bearing mice were anesthetized, and the hair overlying the tumor in each mouse was clipped. In Groups 1 (laser power density: $1 \mathrm{~W} / \mathrm{cm}^{2}$ ), 3 (laser power density: $0.8 \mathrm{~W} / \mathrm{cm}^{2}$ ) and 4 (laser power density: $0.6 \mathrm{~W} / \mathrm{cm}^{2}$ ), the 
Table I. Different concentrations of ICG in solution experiment.

\begin{tabular}{lcccccc}
\hline Group & 1 & 2 & 3 & 4 & 5 & 6 \\
\hline ICG concentration $(\mathrm{mg} / \mathrm{ml})$ & 0.0187 & 0.00935 & 0.00468 & 0.00234 & 0.00117 & 0 \\
\hline
\end{tabular}

ICG, indocyanine green.

Table II. Detailed parameters of different components in photothermal therapy for the treatment of tumor-bearing mice.

\begin{tabular}{lcc}
\hline Group & $\begin{array}{c}\text { Laser power } \\
\text { density }\left(\mathrm{W} / \mathrm{cm}^{2}\right)\end{array}$ & $\begin{array}{c}\text { ICG } \\
\text { concentration }(\mathrm{mg} / \mathrm{ml})\end{array}$ \\
\hline 1 & 1 & 0.10 \\
2 & 1 & 0 \\
3 & 0.8 & 0.10 \\
4 & 0.6 & 0.10 \\
\hline
\end{tabular}

ICG, indocyanine green.

parameters of ICG solution are the same and a total of $200 \mu \mathrm{l}$ of ICG solution was injected into the center of the tumors on the backs of the mice, while in Group 2, 200 of $\mu$ l RPMI-1640 medium was used. Laser irradiation was administered following the ICG solution injection. The different parameters of laser energy were delivered to the tumor sites by optical fibers. An infrared thermometer was used to measure the temperature at the irradiation time points of $0,20,40,60,120,180,240,300$, $360,420,480,540$ and $600 \mathrm{sec}$. The tumor bearing mice were irradiated for $10 \mathrm{~min}$. Temperature measurement images of the tumor bearing mice by forward-looking thermal cameras (FLIR ${ }^{\circledR}$ Systems, Inc, Wilsonville, OR, USA) at different time points during laser irradiation are shown in Fig. 1.

Morphological observation of tumor tissue after laser irradiation. Tumor tissues of the mice from Group 1 were removed on the 1st or 7th day following photothermal therapy. The mice in other groups were sacrificed by spine dislocation. Tissues $(4 \mathrm{~mm})$ were fixed in $10 \%$ buffered formalin $24 \mathrm{~h}$ at $4^{\circ} \mathrm{C}$ and embedded in paraffin. Formalin-fixed paraffin-embedded samples were incubated with paraffin Stretcher (Sakura Finetek Japan, Tokyo, Japan) at $50^{\circ} \mathrm{C}$ overnight, and subsequently stained using Hematoxylin 7211 and Eosin-Y Alcoholic kit (Thermo Fisher Scientific, Inc.) for 10 and $5 \mathrm{~min}$, respectively, at room temperature, as previously described (18). Morphological changes of the tumor tissues were observed using an electronic light microscope (magnification, x10 and x40; Olympus, Tokyo, Japan).

Statistical analysis. All data were derived from at least three independent experiments and are presented as the mean \pm standard error of the mean. The results were evaluated using the independent-samples Pearson's correlation coefficient was used to calculate the coefficient of the fitted spectrum. Student' t-test and one-way analysis of variance
(ANOVA) with Dunnett's multiple comparison post-hoc test. Statistical analysis was performed using SPSS 20.0 software (IBM Corp., Armonk, NY, USA). P<0.05 was considered to indicate a statistically significant difference.

\section{Results}

The absorbance spectrum of ICG. The NIR absorption spectrum of different dilutions of ICG indicated the absorption characteristics of ICG, with an absorption peak ranging from 750 to $800 \mathrm{~nm}$. The detailed spectrum is indicated in Fig. 2. The coefficient of the fitted spectrum curve, which was calculated by Pearson's correlation coefficient is $\mathrm{R}^{2}=0.9942$. There is a commercially available $805-\mathrm{nm}$ laser, which was selected for use in the present study.

Temperature monitoring of water solutions containing different concentrations of ICG during laser treatment. The temperature of water solutions with various concentrations of ICG solution, during laser treatment under a power density of $1 \mathrm{~W} / \mathrm{cm}^{2}$ output, was tested with an infrared thermometer. In group 6 (ICG, $0 \mathrm{mg} / \mathrm{ml})$, the temperature of the water solution without ICG increased $3.5^{\circ} \mathrm{C}$ after $120 \mathrm{sec}$ of $805-\mathrm{nm}$ laser irradiation. In Groups 1 (ICG $0.0187 \mathrm{mg} / \mathrm{ml}$ ) and 2 (ICG $0.00935 \mathrm{mg} / \mathrm{ml}$ ) the temperature increased by $28^{\circ} \mathrm{C}$ and $14^{\circ} \mathrm{C}$, respectively, after $120 \mathrm{sec}$ of irradiation. In group 3 (ICG $0.00468 \mathrm{mg} / \mathrm{ml}$ ), group 4 (ICG $0.00234 \mathrm{mg} / \mathrm{ml}$ ), and group 5 (ICG $0.00117 \mathrm{mg} / \mathrm{ml}$ ), the temperature rose to $5.8^{\circ} \mathrm{C}$, $4.2^{\circ} \mathrm{C}$, and $4.6^{\circ} \mathrm{C}$, respectively. The data in the six groups were evaluated using one-way analysis of variance (ANOVA) with Dunnett's multiple comparison post-hoc test. The temperatures in group 1-5 were significantly increased, compared with Group 6 (ICG, $0 \mathrm{mg} / \mathrm{ml}$; P<0.05). Temperature significantly increased in a ICG concentration-increasing manner. The results indicated that the temperature elevation was almost proportional to the concentration of ICG solution. The characteristics of the temperature variation are presented in Fig. 3.

Temperature monitoring of tumor-bearing mice treated by a laser with or without ICG. In group 2, the temperature of the tumor tissue was elevated by $6.9^{\circ} \mathrm{C}$ at $600 \mathrm{sec}$ after the tumor tissue was treated with a laser $\left(1 \mathrm{~W} / \mathrm{cm}^{2}\right)$ without ICG. In group 1 , the temperature of the tumor tissue was elevated by $28.5^{\circ} \mathrm{C}$ at $600 \mathrm{sec}$ when the tumor tissue was treated with a laser $\left(1 \mathrm{~W} / \mathrm{cm}^{2}\right)$ and ICG $(0.1 \mathrm{mg} / \mathrm{ml})$. The temperature difference between Group 1 and Group 2 was $\sim 20^{\circ} \mathrm{C}$. The temperature in Group 1 was significantly increased, compared with the temperature in Group 2. $(\mathrm{P}<0.05)$. The temperatures in Groups 1 and 2 were analyzed using the independent-samples Student's t-test. The details of the temperature changes are presented in Fig. 4. 


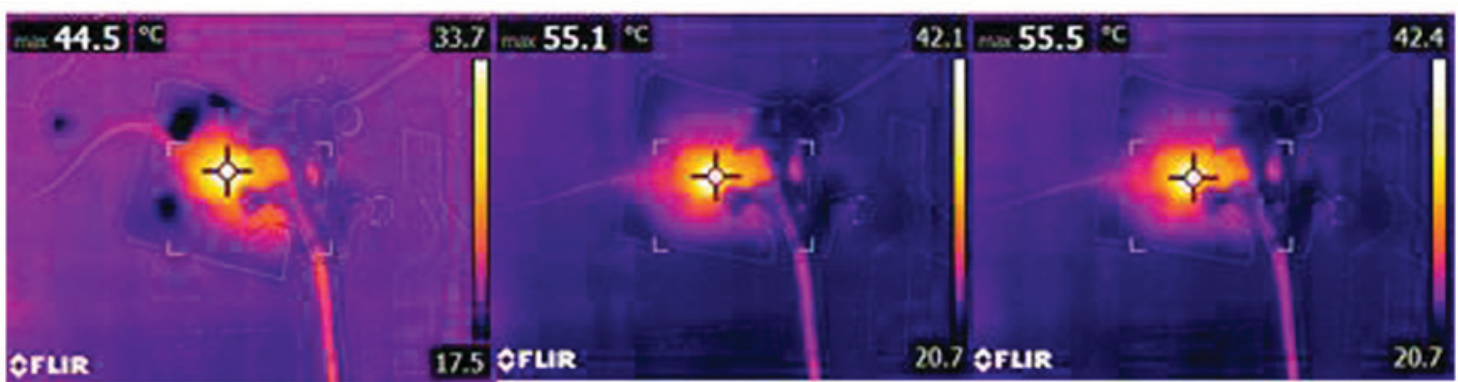

Figure 1. Temperature measurement imaging of tumor bearing mice by infrared thermometer at different time points during laser irradiation.

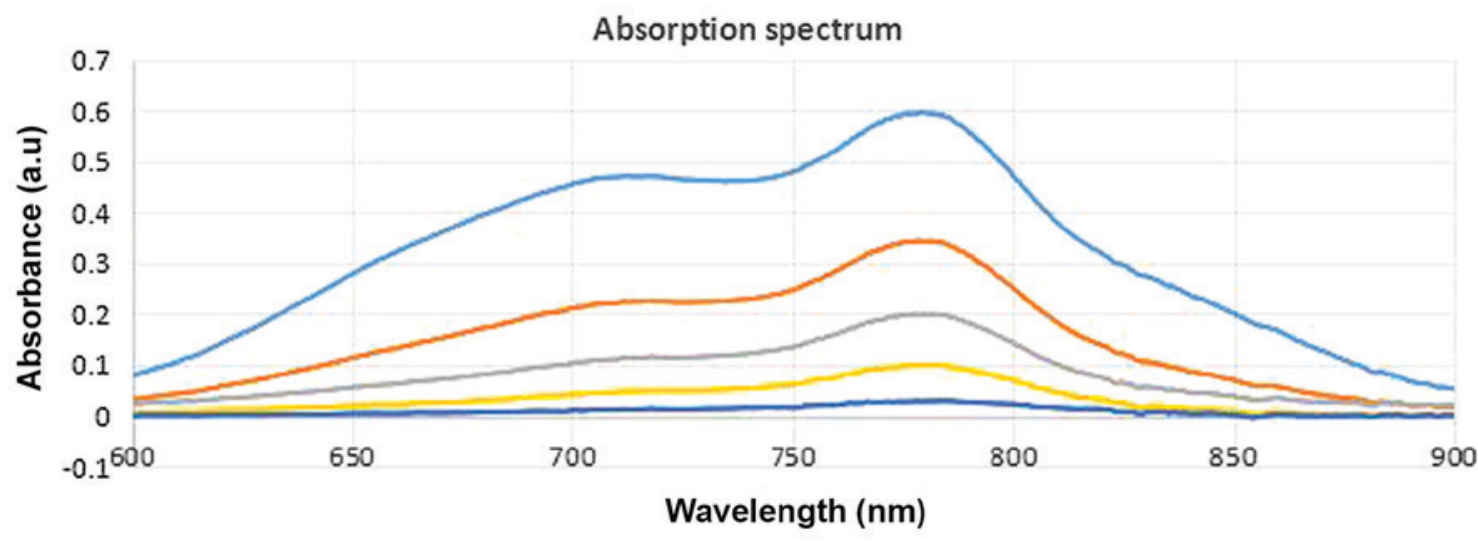

ICG $10 \mu \mathrm{g} / \mathrm{ml} \longrightarrow$ ICG $5 \mu \mathrm{g} / \mathrm{ml} \longrightarrow$ ICG $2.5 \mu \mathrm{g} / \mathrm{ml} \longrightarrow$ ICG $1.25 \mu \mathrm{g} / \mathrm{ml} \longrightarrow$ ICG $0.3725 \mu \mathrm{g} / \mathrm{ml}$

Figure 2. Absorption spectrum of indocyanine green with different concentration.

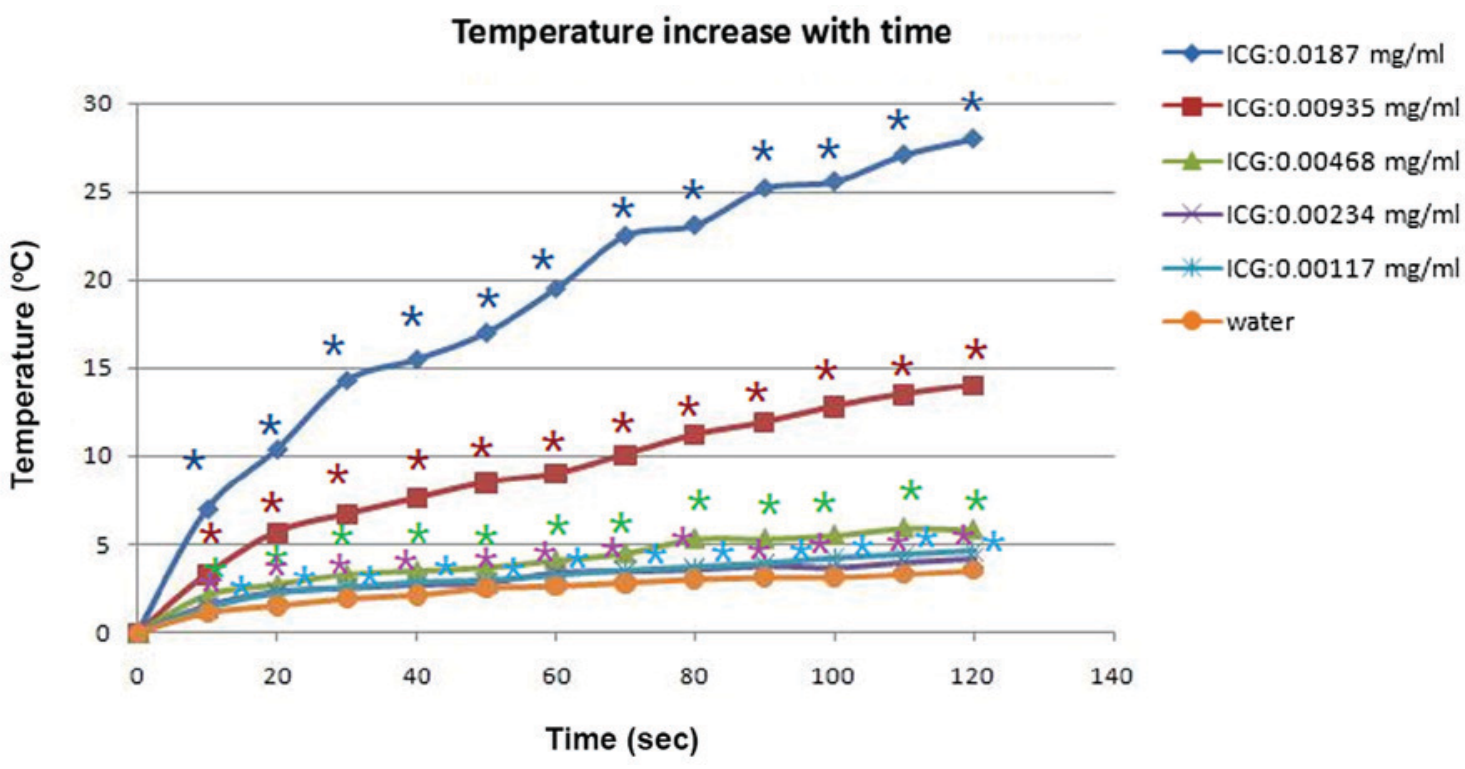

Figure 3. The characteristics of temperature change in water solution with different concentration of indocyanine green during photothermal therapy. Data are presented as the means \pm standard deviations of three identical experiments. " $\mathrm{P}<0.05$ vs. water.

Different parameters of ICG solution. Temperature of the tumor tissue in group 1 (laser power density: $1 \mathrm{~W} / \mathrm{cm}^{2}$ ), group 3 (laser power density: $0.8 \mathrm{~W} / \mathrm{cm}^{2}$ ) and group 4 (laser power density: $0.6 \mathrm{~W} / \mathrm{cm}^{2}$ ) increased by $61.4,58.3$, and $57.1^{\circ} \mathrm{C}$, respectively, at $600 \mathrm{sec}$. The concentration of ICG in these three groups was $0.1 \mathrm{mg} / \mathrm{ml}$. The temperature elevation data are presented in
Fig. 5. In the experiments in the tumor-bearing mice, the results (Fig. 5) demonstrated that the proportion of temperature elevation to laser power density was weak. Group 3 (laser power density: $0.8 \mathrm{~W} / \mathrm{cm}^{2}$ ) and group 4 (laser power density: $0.6 \mathrm{~W} / \mathrm{cm}^{2}$ ) achieved almost the same stable temperature of $\sim 58^{\circ} \mathrm{C}$. The stable temperature of Group 1 (laser power density: $1.0 \mathrm{~W} / \mathrm{cm}^{2}$ ) 


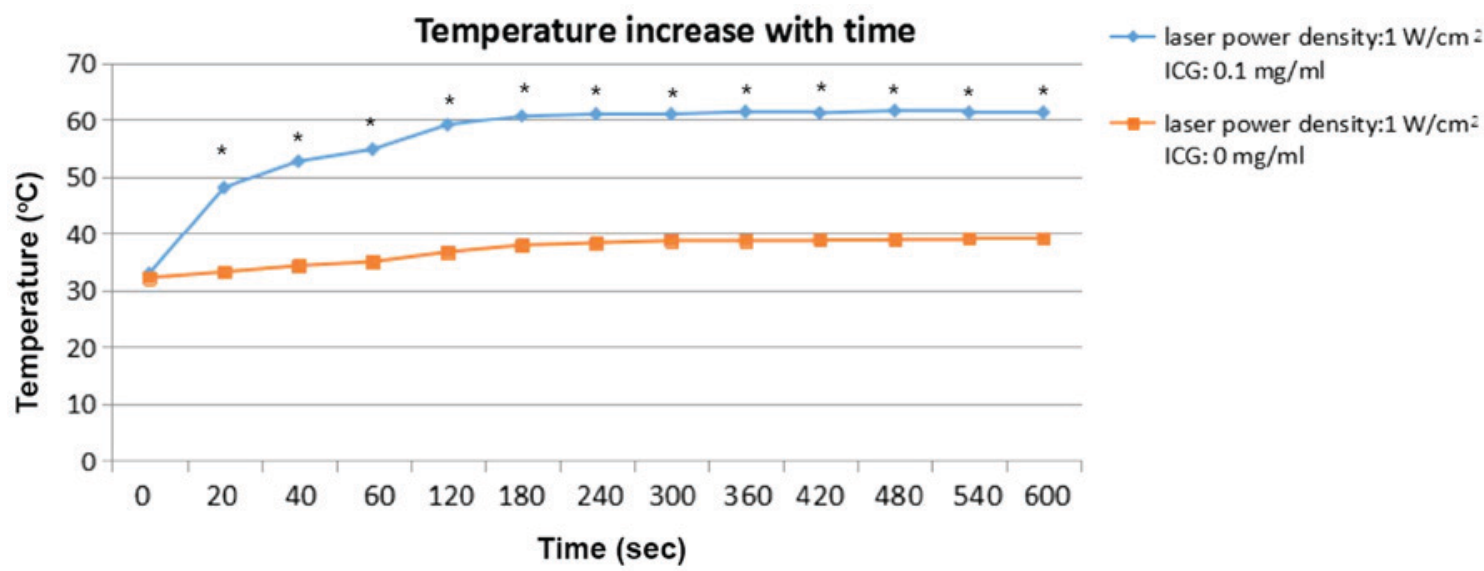

Figure 4. The characteristics of surface temperature change of tumor tissue treated by laser with indocyanine green or without indocyanine green. Data are presented as the means \pm standard deviations of three identical experiments. ${ }^{*} \mathrm{P}<0.05$.

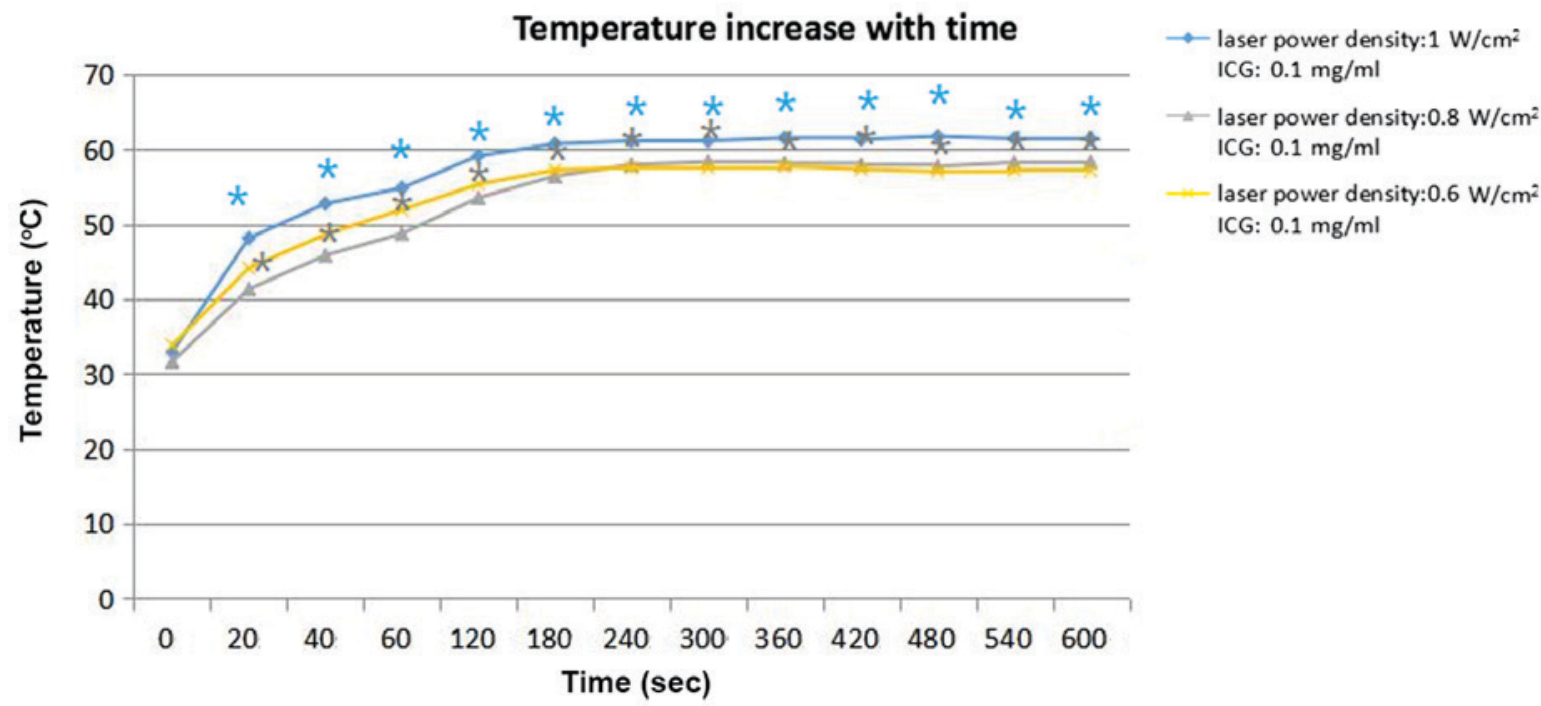

Figure 5. The characteristics of surface temperature change of tumor tissue treated by laser combined with different concentration of indocyanine green. Data are presented as the means \pm standard deviations of three identical experiments. ${ }^{*} \mathrm{P}<0.05$ vs. laser power density: $0.6 \mathrm{~W} / \mathrm{cm}^{2} \mathrm{ICG}: 0.1 \mathrm{mg} / \mathrm{ml}$.

was $8^{\circ} \mathrm{C}$ higher than the stable temperature of Group 3 and 4 . The statistical analysis of the aforementioned results was performed by ANOVA with Dunnett's multiple comparison post-hoc test, indicating that the temperature was significantly increased with increasing laser power density $(\mathrm{P}<0.05)$.

The characteristics of temperature changes with irradiation time. In solution experiments it was indicated that the temperature elevated rapidly from 0 to $60 \mathrm{sec}$ of laser irradiation but only elevated gradually from 100 to $120 \mathrm{sec}$ of laser irradiation (Fig. 3). In the experiment with the tumor bearing mice, the temperature range increased from $30-60^{\circ} \mathrm{C}$ in the first $4 \mathrm{~min}$, and the temperature subsequently became stable after $4 \mathrm{~min}$. (Figs. 4 and 5).

Morphological observations. Surface observations indicated that the tumor tissue from Group 1 (ICG: $0.1 \mathrm{mg} / \mathrm{ml}$; laser power density: $1 \mathrm{~W} / \mathrm{cm}^{2}$ ) did not exhibit any notable changes on the 1st day after irradiation, while tumor tissue necrosis and scabbing were observed on the 7th day.
Fig. 6 indicates the details of the cases with morphological changes in the tumor tissue with $\mathrm{H} \& \mathrm{E}$ staining from Group 1 (ICG: $0.1 \mathrm{mg} / \mathrm{ml}$; laser power density: $1 \mathrm{~W} / \mathrm{cm}^{2}$ ) on the 1 st day and the 7th day following laser irradiation. A complete tumor envelope was detected in the tumor tissue sections from the 1st day following irradiation (Fig. 6A and B). Additionally, a small number of tumor cells experienced necrosis and a small number of inflammatory cells and lymphocytes had infiltrated into the tumor envelope (Fig. 6A and B). In the tumor tissue sections from the 7th day following irradiation it was indicated that the tumor envelopes were almost completed destroyed and were incomplete in the tumor sections (Fig. 6C and D). Additionally, larger areas of tumor tissue experienced necrosis on the 7th day, compared with the 1st day. A large number of inflammatory cells, in particular lymphocytes, had infiltrated into the tumor tissue (Fig. 6C and D). This appeared to be due to laser irradiation, which destroyed the tumor cells and induced tumor tissue necrosis. At the same time, the damaged tumor cells elicited an immune response and induced the accumulation of inflammatory cells around the tumor cells. 

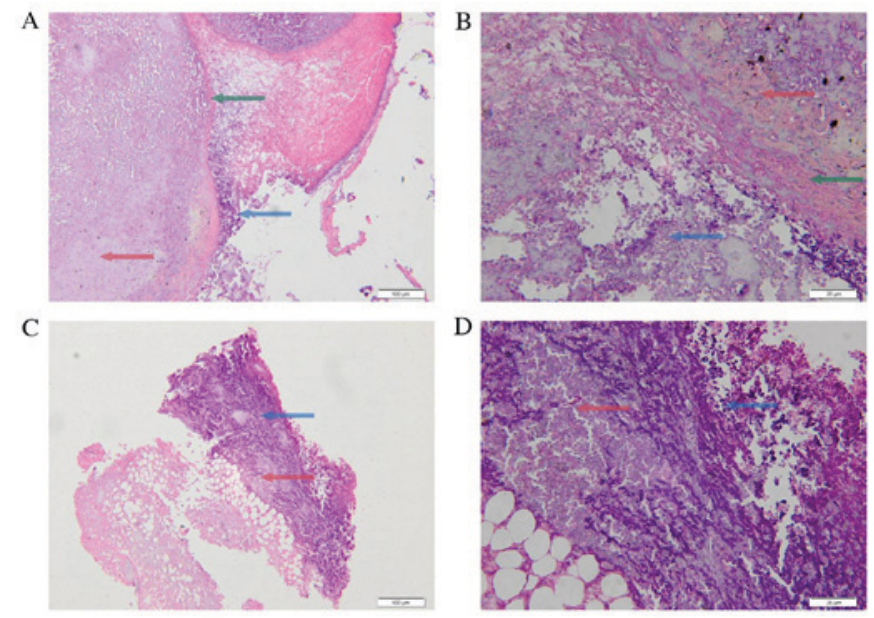

Figure 6. Morphological changes in tumor tissues from Group 1 (ICG $0.1 \mathrm{mg} / \mathrm{ml}$; laser power density: $1 \mathrm{~W} / \mathrm{cm}^{2}$ ) on the $1 \mathrm{st}$ and the 7 th day following treatment combination of laser and ICG. H\&E staining of tumor tissue on the 1st day following irradiation with magnification (A) x100 and (B) x400. H\&E staining of tumor tissue on the 7th day following irradiation with magnification (C) x100 and (D) x400. Green arrow, tumor envelope; red arrow, necrosis; and blue arrow, inflammatory cell. $\mathrm{H} \& \mathrm{E}$, hematoxylin and eosin ICG, indocyanine green.

The immune response was stronger on the 7th day, compared with the 1st day.

\section{Discussion}

Photothermal therapy is a minimally invasive and effective treatment method for cancer (11). It focuses generated heat from absorbed laser energy to directly destroy targeted tumor tissues and to indirectly induce a systemic immune response (19). Laser irradiation can the ability to generate a thermal gradient inside the target tissue, which may produce different biological responses at different temperatures. For example, at a temperature of $43-44^{\circ} \mathrm{C}$, heat erythema can occur. At a temperature of $60-100^{\circ} \mathrm{C}$, coagulation of protein can occur (20). When the temperature is $>105^{\circ} \mathrm{C}$, carbonization and evaporation of tissue occurs, which is an undesirable phenomena in the process of photothermal therapy (11). An extremely high temperature changes the optical property of the tissue, which makes it difficult for light to infiltrate into the deeper tissue (21). Considering the importance of temperature on its biological effects in targeted tissue, the characteristics of temperature changes during the process of photothermal therapy should be investigated.

ICG is a water-soluble anionic tricarbocyanine dye originally used in photography (22). ICG has been approved by the USA Food and Drug Administration for clinical applications (17). The characteristics of ICG are NIR absorption and fluorescence, making ICG suitable for bio-imaging applications (23). ICG can be used for ophthalmologic angiography, measuring cardiac output, hepatic functional studies, and guiding biopsies, for example of breast cancer (24). ICG has also been used in photodynamic therapy by producing reactive oxygen species to destroy tumor tissue (25). Furthermore, ICG can absorb a specific spectrum of light from a laser and produce a thermal effect subsequently to being injected into a tumor (24). The combination of ICG and a laser can produce a selective tumor thermal effect (7).
In the present study, in the solution experiments, the temperature elevation was almost proportional to the concentration of the ICG solution when the same laser power density was applied. In the tumor-bearing mice expriments, the results demonstrated that the proportion of temperature elevation to laser power density was weak. Compared with the concentration of ICG, the contribution of the laser power density to the temperature elevation was indicated to be small. Kannadorai and Liu (26) reported that there was almost no increase in the overall temperature of the tumor during photothermal therapy as the laser power density was steadily increased.

When the solution and the tumor-bearing mice were irradiated by a laser without any ICG there was no notable elevation in temperature, compared with those treated with a laser combined with ICG. Results indicated that the temperature difference between the only-laser group and the combined group could be up to $20^{\circ} \mathrm{C}$. Therefore, the present study demonstrated that ICG, as a photosensitizer, contributed significantly to temperature elevation. Wang et al (27) demonstrated that the combination of ICG and NIR could selectively destroy the targeted tissue, reaching up to $1.5 \mathrm{~cm}$ in depth, with minimal damage to the overlying surface tissue. Additionally, it was indicated that by extending irradiation time, the temperature quickly increased in the first 4 min and subsequently leveled off after 4 min.

Morphological changes of the tumor tissue demonstrated that photothermal therapy have the ability to elicit an immune reaction, in addition to the heat effect. On the 7th day, the immune reaction was stronger, compared with the 1st day. Previous studies have demonstrated that different temperatures achieved in the targeted tissue can elicit different biological immune responses, including innate immune responses and acquired immune responses $(7,28)$. Thermal interactions at heat shock temperatures are not sufficiently high enough to kill tumor cells directly (29). In heat shock temperatures ranging from 41 to $43^{\circ} \mathrm{C}$ however, injured tumor cells are more sensitive to the immune system, as heat denatures tumor antigens (30) can modulate immune cells and cytokines. Cytotoxic temperatures are increased, comprared with heat-shock temperatures (31). In the cytotoxic temperature range, $>43^{\circ} \mathrm{C}$, tumor cells can be directly killed, as numerous tumor cells disintegrate, therefore, releasing antigens. However, the optimal time and temperature at which photothermal therapy can stimulate the strongest immune effect still requires further research.

The temperature of tumor tissue is not exclusively dependent on the power density, ICG concentration and irradiation time. There are numerous other factors that can influence temperature, particularly in vivo (32). First, energy loss is associated to blood flow (32). The temperature distribution in vivo is usually non-uniform, due to tissue cooling by blood flow (33). The aforementioned phenomenon remains a challenge to avoid. Secondly, tissue heterogeneity is another factor that influences temperature elevation (34). Different types of tumor tissues have different optical properties, which generate different temperatures in different tumor tissues or in different parts of a tumor, with the same laser power. Thirdly, tumor volume also has an effect on temperature distribution (35) as smaller tumors have a more optimal temperature distribution, compared with larger tumors (32). 
A number of treatment strategies have been reported decrease heterogeneity; however, to the best of our knowledge, almost all biological therapeutic interventions have not been able to overcome the basic neoplastic heterogeneity (34). The efficacy of photothermal therapy itself for tumor treatment is limited. Combination therapy is the current trend in cancer treatment. The combination of photothermal therapy and immunotherapy, called laser immunotherapy, has exhibited promising effects $(28,36)$. Laser immunotherapy has significantly prolonged the survival time of tumor bearing mice that successfully rejected the second inoculation of tumor cells (4). Radiotherapy can convert 'cold' tumors into 'hot' tumors. 'Cold' tumors indicate less immunogenicity and are not affected by immunotherapy, while 'hot' tumors are infiltrated with T cells and therefore are sensitive to immunotherapy (37). Taking the aforementioned into consideration, laser immunotherapy may be able to guide the immune system to attack refractory types of cancers and sensitize these refractory tumors to immune therapy by recruiting antitumor $\mathrm{T}$ cells, as indicated in radiotherapy. Therefore, it is important to control local temperature elevations within an appropriate range, where high temperatures can both damage tumor cells and elicit strong immune responses.

In photothermal therapy, the concentration of photosensitizer and the laser power density are important determinates of the temperature elevation. In the present study, the temperature rise was almost proportional to the concentration of ICG solution and the laser power density. The concentration of ICG strongly contributed to the temperature rise compared with the laser power density. Following the combination of laser with ICG, temperature was significantly increased in the solution and in tumor-bearing mice. By extending exposure time, the temperature rose quickly at the beginning and then stabilized. Results suggested that photothermal therapy may not only induce tumor necrosis, but may also induce lymphocyte infiltration. The characteristics of temperature changes play an important role in the application of photothermal therapy. Further studies are needed to investigate the optimal temperature for the generation of an optimal thermal and immune effect.

\section{Acknowledgements}

The authors would like to acknowledge the support provided by the Biophotonics Research Laboratory Center (OK, USA).

\section{Funding}

This study was partly supported by the National Key Research and Development Program of China (no. 2018YFB0407200) and was supported in part by a grant from National Natural Science Foundation of China (no. 81572953).

\section{Availability of data and material}

All data generated or analyzed during this study are included in this published article.

\section{Authors' contributions}

SL performed the majority of the experiments and wrote the manuscript. XL designed the experiment and analyzed the data. FZ assisted in conducting the experiment and analyzed experiment data. YX participated in the design of the experiment, performed experiments and partcipated in drafting of the manuscript. YY was involved in revising the manuscript and analyzing the data. BW and YF participated the analysis and interpretation of data. ND was involved in revising the manuscript and analyzing the data. All authors have read and approved the final version of this manuscript.

\section{Ethics approval and consent to participate}

All animal experiments were approved by the Institutional Animal Care and Use Committee and were in compliance with National Institutes of Health guidelines. In addition, tumor burden did not exceed the recommended dimensions and animals were anesthetized and sacrificed using acceptable method techniques.

\section{Patient consent for publication}

Not applicable.

\section{Competing interests}

The authors declare that they have no competing interests.

\section{References}

1. Siegel RL, Miller KD and Jemal A: Cancer statistics, 2017. CA Cancer J Clin 67: 7-30, 2017.

2. Wu F: Heat-based tumor ablation: Role of the immune response. Adv Exp Med Biol 880: 131-153, 2016.

3. Li X, Le H, Wolf RF, Chen VA, Sarkar A, Nordquist RE, Ferguson H, Liu H and Chen WR: Long-term effect on EMT6 tumors in mice induced by combination of laser immunotherapy and surgery. Integr Cancer Ther 10: 368-373, 2011.

4. Chen WR, Adams RL, Carubelli R and Nordquist RE: Laser-photosensitizer assisted immunotherapy: A novel modality for cancer treatment. Cancer Lett 115: 25-30, 1997.

5. Le K, Li X, Figueroa D, Towner RA, Garteiser P, Saunders D, Smith N, Liu H, Hode T, Nordquist RE and Chen WR: Assessment of thermal effects of interstitial laser phototherapy on mammary tumors using proton resonance frequency method. J Biomed Opt 16: 128001, 2011.

6. Li X, Ferrel GL, Guerra MC, Hode T, Lunn JA, Adalsteinsson O, Nordquist RE, Liu H and Chen WR: Preliminary safety and efficacy results of laser immunotherapy for the treatment of metastatic breast cancer patients. Photochem Photobiol Sci 10: 817-821, 2011.

7. Bailey CA, Cowan TM, Liu VG, Lemley EC and Chen WR: Optimization of selective hyperthermia. J Biomed Opt 9: 648-654, 2004.

8. Slovak R, Ludwig JM, Gettinger SN, Herbst RS and Kim HS: Immuno-thermal ablations-boosting the anticancer immune response. J Immunother Cancer 5: 78, 2017.

9. Vankayala R, Huang YK, Kalluru P, Chiang CS and Hwang KC: First demonstration of gold nanorods-mediated photodynamic therapeutic destruction of tumors via near infra-red light activation. Small 10: 1612-1622, 2014.

10. Vankayala R, Lin CC, Kalluru P, Chiang CS and Hwang KC: Gold nanoshells-mediated bimodal photodynamic and photothermal cancer treatment using ultra-low doses of near infra-red light. Biomaterials 35: 5527-5538, 2014.

11. Hou X, Tao Y,Pang Y,Li X, Jiang G and Liu Y: Nanoparticle-based photothermal and photodynamic immunotherapy for tumor treatment. Int J Cancer 143: 3050-3060, 2018.

12. Crochet JJ, Gnyawali SC, Chen Y, Lemley EC, Wang LV and Chen WR: Temperature distribution in selective laser-tissue interaction. J Biomed Opt 11: 34031, 2006.

13. Li X, Naylor MF, Le H, Nordquist RE, Teague TK, Howard CA, Murray C and Chen WR: Clinical effects of in situ photoimmunotherapy on late-stage melanoma patients: A preliminary study. Cancer Biol Ther 10: 1081-1087, 2010. 
14. Zhou F, Li X, Naylor MF, Hode T, Nordquist RE, Alleruzzo L, Raker J, Lam SS, Du N, Shi L, et al: InCVAX-a novel strategy for treatment of late-stage, metastatic cancers through photoimmunotherapy induced tumor-specific immunity. Cancer Lett 359: $169-177,2015$.

15. Taylor JS, Zeki J, Ikegaki N, Chen LL and Chiu B: Combined application of Indocyanine green (ICG) and laser lead to targeted tumor cell destruction. J Pediatr Surg 53: 2475-2479, 2018.

16. Sandberg K and Umans JG; Georgetown Consensus Conference Work Group: Recommendations concerning the new U.S National Institutes of Health initiative to balance the sex of cells and animals in preclinical research. FASEB J 29: 1646-1652, 2015.

17. Hou G, Yao Y and Wang G: Inhibitory effect of quercetin on ACC-M cell xenografts in nude mice in vivo. J Oral Sci Res 34: 554-557, 2018.

18. Kourea $\mathrm{H}$ and Kotoula V: Towards tumor immunodiagnostics. Ann Transl Med 4: 263, 2016.

19. Liang C, Diao S, Wang C, Gong H, Liu T, Hong G, Shi X and Liu Z: Tumor metastasis inhibition by imaging-guided photothermal therapy with single-walled carbon nanotubes. Adv Mater 26: 5646-5652, 2014.

20. Zhang HG, Mehta K, Cohen P and Guha C: Hyperthermia on immune regulation: A temperature's story. Cancer Lett 271: 191-204, 2008

21. Iizuka MN, Vitkin IA, Kolios MC and Sherar MD: The effects of dynamic optical properties during interstitial laser photocoagulation. Phys Med Biol 45: 1335-1357, 2000.

22. Fox IJ, Brooker LG, Heseltine DW, Essex HE and Wood EH: A tricarbocyanine dye for continuous recording of dilution curves in whole blood independent of variations in blood oxygen saturation. Proc Staff Meet Mayo Clin 32: 478-484, 1957.

23. Giraudeau C, Moussaron A, Stallivieri A, Mordon S and Frochot C: Indocyanine green: Photosensitizer or chromophore? Still a debate. Curr Med Chem 21: 1871-1897, 2014.

24. Li X, Min M, Du N, Gu Y, Hode T, Naylor M, Chen D, Nordquist RE and Chen WR: Chitin, chitosan, and glycated chitosan regulate immune responses: The novel adjuvants for cancer vaccine. Clin Dev Immunol 2013: 387023, 2013.

25. Porcu EP, Salis A, Gavini E, Rassu G, Maestri M and Giunchedi P. Indocyanine green delivery systems for tumour detection and treatments. Biothchnol Adv 34: 768-789, 2016.

26. Kannadorai RK and Liu Q: Optimization in interstitial plasmonic photothermal therapy for treatment planning. Med Phys 40: 103301, 2013.
27. Wang LV, Nordquist RE and Chen WR: Optimal beam size for light delivery to absorption-enhanced tumors buried in biological tissues and effect of multiple-beam delivery: A Monte Carlo study. Appl Opt 36: 8286-8291, 1997.

28. Wang C, Xu L, Liang C, Xiang J,Peng R and Liu Z: Immunological responses triggered by photothermal therapy with carbon nanotubes in combination with anti-CTLA-4 therapy to inhibit cancer metastasis. Adv Mater 26: 8154-8162, 2014.

29. Yoon TJ, Kim JY, Kim H, Hong C, Lee H, Lee CK, Lee KH, Hong S and Park SH: Anti-tumor immunostimulatory effect of heat-killed tumor cells. Exp Mol Med 40: 130-144, 2008.

30. Kleinovink JW, Fransen MF, Löwik CW and Ossendorp F: Photodynamic-immune checkpoint therapy eradicates local and distant tumors by $\mathrm{CD}^{+} \mathrm{T}$ cells. Cancer Immunol Res 5: 832-838, 2017.

31. Li X and Chen WR: Laser immunotherapy: Novel modality to treat cancer through specific antitumor immune response. Chin J Lasers 37: 2698-2702, 2010.

32. Dillon C, Roemer R and Payne A: Magnetic resonance temperature imaging-based quantification of blood flow-related energy losses. NMR Biomed 28: 840-851, 2015.

33. Ganguly M, Miller S and Mitra K: Model development and experimental validation for analyzing initial transients of irradiation of tissues during thermal therapy using short pulse lasers. Lasers Surg Med 47: 711-722, 2015.

34. Lee SS, Roche PJ, Giannopoulos PN, Mitmaker EJ, Tamilia M, Paliouras $M$ and Trifiro MA: Prostate-specific membrane antigen-directed nanoparticle targeting for extreme nearfield ablation of prostate cancer cells. Tumour Biol 39: 1010428317695943, 2017.

35. Gnyawali SC, Chen Y, Wu F, Bartels KE, Wicksted JP, Liu H, Sen CK and Chen WR: Temperature measurement on tissue surface during laser irradiation. Med Biol Eng Comput 46: 159-168, 2008.

36. Chen Q, Xu L, Liang C, Wang C, Peng R and Liu Z: Photothermal therapy with immune-adjuvant nanoparticles together with checkpoint blockade for effective cancer immunotherapy. Nat Commun 7: 13193, 2016.

37. Demaria S, Coleman $\mathrm{CN}$ and Formenti SC: Radiotherapy: Changing the game in immunotherapy. Trends Cancer 2: 286-294, 2016. 